\title{
LA DIVERSIDAD EN EL AULA, EL GRAN DESAFÍO EN LA ACTUALIDAD. ¿ESTÁN EL Y LA DOCENTE PREPARADOS PARA ENFRENTARLO?
}

\author{
M.Ed. Erica Vásquez ${ }^{l}$ \\ "...no te salves ahora \\ ni nunca \\ no te salves \\ no te llenes de calma \\ no reserves del mundo \\ sólo un rincón tranquilo \\ no dejes caer los párpados \\ pesados como juicios..."
}

Benedetti

\section{Resumen}

En la actualidad, Costa Rica cuenta con una población muy variada de niños y niñas en las aulas que, por factores como la migración, las diferencias socioeconómicas y otras, han convertido el aula en un espacio multicultural. La diversidad en el aula, por lo tanto, es un gran desafio para el y la docente, quienes deben atender a estudiantes con características sumamente variadas y ofrecerles una educación acorde con sus necesidades individuales. El contar con los conocimientos para atender el aula multicultural, es un reto que conlleva un cambio de actitud hacia los "Otros". Esto solamente se puede lograr a través de la aceptación de estos como seres humanos únicos y diferentes, personas que poseen una visión de mundo construida a través de las experiencias vividas a lo largo de su vida, las cuales deben ser tomadas en cuenta a la hora de enseñarles,

1 Académica de la División de Educación Básica, donde actualmente se desempeña como Subdirectora. Máster en Pedagogía con énfasis en Diversidad en los Procesos Educativos. 
porque de ello dependerá el éxito o el fracaso que se logre. Por lo anterior, es de suma importancia conocer diferentes enfoques que discuten sobre diversidad y multiculturalidad hoy en día, ya que ofrecen luz para guiarnos en el camino adecuado a seguir para enfrentar esta compleja realidad.

\section{Palabras claves}

Diversidad, multiculturalidad, migrantes, aulas multiculturales, educación multicultural, currículo multicultural, educadores.

\section{Abstract}

Nowadays, Costa Rican classrooms have become multicultural spaces, characterized by the presence of children from diverse populations, especially because of phenomena such as migrations, but also due to social and economical factors. As a result, diversity within the classroom represents a big challenge for teachers, who are required to educate students with truly dissimilar characteristics while offer them an education in accordance with their specific individual needs. Teaching in the multicultural classroom is a challenge that involves a change of attitude to the "Others". This can only be achieved through the recognition of students as unique and different human beings, people who have a view of the world built through specific life experiences; experiences that have to be taken into account when teaching because this is the basis to succeed or fail as educators. Consequently, it is important to know different approaches that discuss diversity and multiculturalism at the present time, giving us light to find the correct path in order to face this complex reality.

\section{Key words}

Diversity, multicultural, migrants, multicultural classroom, multicultural education, multicultural curriculum, teachers.

E

ntender la diversidad presente, actualmente, en las aulas es indispensable y, para ello, hay que ubicarse en la realidad que se vive en Costa Rica. Realidad que se puede expresar en cifras que muestra el Estado de la Nación, y en la cuales, para el 2002, el número de personas pobres se estimaba en 916.000; según sus datos, uno de cada cuatro jóvenes se encontraba fuera del sistema educativo costarricense. Igualmente se calcula que más de 600.000 inmigrantes han entrado al país en menos de 5 años, y de ellos un alto porcentaje asiste a escuelas costarricenses.

El incremento en la entrada de migrantes al país ha ido cambiado el panorama del sistema educativo nacional. De acuerdo con el Departamento de Estadística del Ministerio de Educación Pública, en 1990, se registraron 
12.643 estudiantes migrantes matriculados en la educación regular, para el año 1999 la cifra ascendió a 30.136 estudiantes, mientras que para el año 2004 se encuentran reportados 45.899 migrantes matriculados en el sistema educativo. Si bien, esto demuestra un crecimiento considerable en la población, puede decirse que es mayor en la realidad, pues muchas veces los datos no son exactos debido a que no se incluyen en estas cifras a los niños y niñas, hijos e hijas de migrantes nacidos en Costa Rica. Además, en algunos casos, la constante migración interna de estos en el país, imposibilita que se contabilicen adecuadamente.

La realidad social del país en relación con los y las migrantes también se puede expresar con rostros y nombres que el sistema educativo acoge en sus aulas y que forman una población muy diversa. Dentro de este contexto, se encuentra Enrique, un niño migrante proveniente de un lugar llamado La Palmera en Nicaragua, quien es tan sólo una milésima parte de ese mosaico de culturas, anhelos, sueños y sufrimientos que hoy caracteriza al país. Sobre Enrique y los miles de niños y niñas que asisten a las aulas costarricenses, se ha hablado en múltiples foros, y se han tomado decisiones acertadas que, de ser puestas en práctica, solucionarían no solamente la situación educativa de Enrique, sino que enriquecerían la de sus compañeros y compañeras. Sin embargo, al terminar los foros, los ausentes son en su mayoría los y las docentes que deberían llevar estas propuestas a la realidad de aula, dado que no tienen acceso a la capacitación adecuada y no cuentan con espacios para compartir y, en conjunto, encontrar posibles soluciones para la realidad de aula que viven a diario.

En un largo o corto plazo, Enrique no será más que una estadística que dirá que pasó a ser parte del porcentaje de uno por cada cuatro niños y niñas, alejados de las aulas. Esta es una historia de todos los días, que se repite por múltiples razones, complicadas y únicas; no obstante, el y la docentes son de los pocos que tienen el conocimiento y el poder para cambiar estos resultados.

La atención a la multiculturalidad y diversidad en el aula escolar es indispensable, para dar una respuesta a las necesidades específicas de los y las docentes que atienden en sus aulas a niños y niñas como Enrique. Como lo dice Barberousse (2003, p. 8), "la atención a la diversidad, entendida desde la pedagogía crítica como lucha por la igualdad y como lucha por la construcción de una educación integradora y compensadora de desigualdades, implica elaborar proyectos educativos que contribuyan a compensar y superar las desigualdades en lugar de reproducirlas o aumentarlas". 
En un país como Costa Rica, los y las docentes no pueden darse el lujo de no preguntarse, qué tipo de docente reclama la realidad social y educativa. Y al preguntarse esto, deberán hacerlo con el conocimiento de que las escuelas costarricenses poseen características diferentes a las que presentaban hace unas cuantas décadas, sobre todo en el marco de una visión de la diversidad, y hoy se presentan como el acumulado de cambios y transformaciones en los años anteriores. López (s.f.) comenta que el hecho de anunciar que el fenómeno educativo está inmerso en el desenvolvimiento político e ideológico de cualquier sociedad, es sólo reconocer lo que es evidente. De forma acertada, afirma que los tiempos cambian, que el romanticismo educativo de los años sesenta ha dado paso, en los setenta a una época cargada de incertidumbres y a una década de los ochenta desilusionada o desilusionante. Los años noventa, por su parte, se caracterizaron por los problemas económicos, la escasa inversión en educación, unidos a los problemas de natalidad y a la falta de concientización hacia el cambio anunciado, lo cual retrasa el movimiento de mejora en nuestra sociedad.

Todo este largo recorrido ha marcado, en parte, el quehacer docente, y a su vez se ha ido entretejiendo con diferentes variantes que contribuyen con el sistema educativo actual y que, en parte, no corresponden a un modelo para darle atención adecuada a la situación existente.

Cada docente debería salir a trabajar con la certeza de que no lo sabe todo, de que debe aprender en el camino y que para lograr con éxito llevar a las aulas mucho más que conocimientos, no basta con las buenas intenciones, sino con una praxis que sólo puede derivarse de una capacitación constante y una búsqueda por conocer el entorno y hallar soluciones viables a los problemas que se le presentarán.

Es hora de encontrar la respuesta abriendo los ojos a la realidad y enfrentarla. Mañana, el y la docentes podrían estar a cargo de cuarenta niños y niñas en un salón de clases, donde se mezclan todas las individualidades que se pueden imaginar y las impensables también. Es evidente que esta realidad irá transformando el aula en una muestra del mundo en miniatura. Como lo comenta López (s.f.), cada ser humano se diferencia singularmente de los otros no por razones biológicas, sino porque hay distintos modos de creencias, comportamientos y puntos de vista, y agrega que, es allí donde el respeto a la diferencia implica el reconocimiento de ser diverso, y la tolerancia se convierte en el valor esencial que necesita la cultura de la diversidad.

Ante este panorama, las fórmulas mágicas y las recetas no existen, tan sólo las vivencias de otros y otras docentes que podrían ser utilizadas 
como punto de referencia para iniciar las labores cada día, agregando siempre la propia inventiva y experiencia. Se debe tratar de aprender de los y las otras, y de las propias experiencias, mejorando el quehacer que nos lleve a ser educadores y educadoras, y no meros informadores e informadoras, de tal forma que los invoque, como dice Benedetti (1980), a no salvarse ahora ni nunca, ya que la realidad demanda, moral y éticamente, que se dé la talla en la profesión que se escogió ejercer.

Cabe aquí agregar, como lo dice Barberousse (2003, p. 9) que se trata de favorecer la igualdad de oportunidades:

“...y la comprensión de las desigualdades mediante una enseñanza comprensiva e inclusiva como garante de la atención a la diversidad en sus más variadas modalidades y expresiones: cultural, étnica, de género, cognitiva, social, económica, política, religiosa, de acceso a información, de lugar que se ocupa en el proceso productivo, ética, moral, de sensibilidad, afectiva y emocional. Sentimos distinto, necesitamos distinto, actuamos distinto, pero podemos estimarnos y querernos tal como somos si logramos establecer causes de participación e interconexión entre las más variadas maneras de vivir; celebrar o mirar la vida".

Para poder lograr lo anterior, es necesario que los y las docentes cuenten con una actitud de apertura, que traten día con día de dejar los prejuicios a un lado y conviertan en propia la lucha por los derechos de todos los niños y niñas. Hay que abandonar el "rincón tranquilo" de la vida, y disponerse a ser verdaderos docentes: se puede cambiar el mundo poco a poco y abrir las puertas más cerradas.

Es indispensable comenzar a mirar más allá de lo que se muestra a simple vista y saber que el color de la piel, la raza, la condición social, el género, las necesidades educativas especiales, la discapacidad, la nacionalidad, son tan sólo variables que enriquecen el contexto del aula, y un regalo de innumerables colores, para que se pueda tener una realidad más completa y valiosa. Nos encontramos en una época donde la importancia reside en las diferencias como referente para la construcción de una nueva escuela y una sociedad que abran las puertas a la diversidad, como cambio de pensamiento, y permiten mejorar la calidad de vida de todas las personas, independientemente de su condición.

Lo diferente es lo que enriquece y hace a cada persona única; esa visión de mundo que pone todo al revés y al instante le da vuelta de nuevo. Esto 
es necesario para lograr ver a cada niño y niña en su totalidad, como un ser único e irrepetible y no como una estadística más.

En la actualidad, la existencia de aulas multicuturalmente diversas es una realidad que no se puede olvidar ni negar. Por el contrario, requiere de toda la atención posible para darle la oportunidad, tanto a Enrique como a los niños y las niñas que la viven, de insertarse en la sociedad y, sobre todo, de construir las bases para un futuro mucho mejor que el actual. Desde esta perspectiva, el aula escolar multiculturalmente diversa no debe ser vista como un problema, sino como un reto para el y la docentes que, por la naturaleza de su profesión, han de velar porque los y las estudiantes, no importa del lugar de procedencia, tengan la oportunidad de lograr un proceso de enseñanza y aprendizaje acorde con sus necesidades y con el entorno al cual pertenecen.

Para estos niños y niñas, no es suficiente con ofrecerles una silla y una mesa; en el mejor de los casos, debe brindárseles ayuda integral que englobe lo académico, lo social y lo afectivo para que, realmente, pueda decirse que están teniendo acceso a una educación digna y eficaz. En esta misma línea, López (s.f.) manifiesta que, el discurso de la diversidad y de la escuela pública es preferentemente ético, ya que se relaciona con la moral y se convierte en otra manera de entender al ser humano y a la sociedad. Agrega que es imperante que ante la cultura de la diversidad y la calidad de vida, se introduzca una nueva axiología y un nuevo mundo de valores, en los cuales las personas han de ser respetadas por ser personas y no por el lugar que ocupen en la sociedad, y afirma que esta será la única forma de entender que ser diferente es un valor y no un defecto.

El abordar el tema del aula escolar en un marco de la diversidad representa un primer paso en la lucha contra la injusticia y la falta de atención que está sufriendo Enrique en este momento, al igual que otros tantos miles de niños y niñas en el aula; también, es una lucha contra la ignorancia que provoca heridas irreparables con el tiempo, una lucha por el respeto a una calidad de vida que resalta las diferencias. Para Gimeno Sacristán (1998), la práctica educativa es entendida como la acción orientada, la cual tiene sentido en la práctica en la que el individuo posee un papel fundamental como agente insertado en la estructura social. Así, la práctica se convierte en una actividad que desarrolla a los agentes personales, ocupando y dando contenido a la experiencia de enseñar y educar.

Este tipo de práctica educativa es la que se pretende visualizar en el aula escolar multicultural, ya que en este caso es de primordial importancia entender que el individuo tiene que ser visto como un cúmulo de vivencias 
propias, parte de su nacionalidad y parte de su historia de vida marcada por diferentes acontecimientos, muy distintos a los de cualquier otro, pero insertado en la sociedad costarricense que, vista de lo macro a lo micro, se reduce por un momento a la comunidad en la cual reside y al aula a la cual asiste cada día. Este agente externo a la cultura costarricense, llena de múltiples matices la cotidianeidad de la vida escolar; por lo tanto, su desarrollo deberá contemplarse, trabajarse e integrarse, pero sin cercenar su propio ser individual.

La diversidad no debe ser vista como un actor pasivo en los salones de clases; por el contrario, ha de contemplarse como una variable en las actividades de cada día, dentro de un marco de la comprensión, la tolerancia y la empatía para aquellas personas que hoy comparten con nosotros este país. Tal y como lo rescata Alvarenga (1997), todo ser humano tiene derecho a un pedacito en cualquier rincón de la tierra, así pues con más razón puede decirse que tiene derecho a una educación de equidad con una visión de la diversidad, como parte inherente al ser humano; debe ser conocida, respetada $\mathrm{y}$ atendida.

El aula multiculturalmente diversa está presente hoy en todas las escuelas, ya sean públicas o privadas, del sistema educativo nacional. Lo anterior debido a las migraciones, el vivir en un mundo que se achica cada día y en el que se comienzan a borrar las fronteras. El advenimiento de escuelas desterritorializadas, escuelas de un mundo globalizado que no están conformadas por estudiantes pertenecientes a una comunidad específica o a un territorio definido, donde los alumnos y las alumnas viajan desde diferentes lugares, en su mayoría, lejos de la institución, presentan características muy variadas tanto geográfica, como social y económicamente. Estas escuelas se sitúan en centros de provincia y en ellas muchos factores convergen para dar una gran cantidad de culturas en un espacio tan reducido como es el salón de clases, lo que convierte a cada aula en una muestra del mundo en miniatura.

Es aquí donde el y la docentes se enfrentan con el desafío de proveer una educación de calidad y justa para todos los y las participantes, pues deben replantearse las nociones aprendidas en la academia y recrear en sus mentes un mundo totalmente distinto al que les fue enseñando. Todo esto cargando con un currículo no inclusivo y con un bagaje cultural que aboga por un etnocentrismo exacerbado y dañino, que no deja aprovechar la riqueza cultural que se despliega en el aula.

La integración de diversas culturas en el salón de clases es un proceso difícil, que desgarra muchas veces lo más interno de las creencias y lesiona 
lo que se cree es la identidad. Pero a la vez, lleva a un encuentro con los Otros, lo cual hace a la persona ser más completa sin dejar de ser quien es. De esta forma, hacemos nuestras las palabras de Magris (2000) citado por Barberousse (2001, p. 24), donde refiere que "...la utopía da sentido a la vida, porque exige, contra toda verosimilitud, que la vida tenga sentido".

¿Están la y el docentes preparados para esto? ¿Comprenden de qué se trata? ¿Vislumbran el alcance de estos cambios en su salón de clases? ¿Son capaces de soñar con esta utopía multicultural, muchas veces ignorada? Se espera que así sea, pues el multiculturalismo desafia la realidad y no se marcha, y exige a gritos una respuesta. ¿O acaso deberá Enrique conformarse tan solo con una silla y un pupitre en el mejor de los casos, y no con una educación de calidad que dé respuesta a sus necesidades?

El primer paso que se debe dar, para encontrar las respuestas a las necesidades de niños y niñas en la misma situación que Enrique, es el entender, tal y como lo plantea Bueno (1998), que cada grupo no es otra cosa que una organización de la diversidad, de la heterogeneidad intragrupal inherente a toda sociedad humana, y que es allí donde la idea de una diversidad organizada remite a la existencia en un grupo de tantas versiones sobre el mundo y la vida como individuos la compongan, con versiones diferentes pero equivalentes sobre el mismo. Lo anterior, de tal manera, que las diferencias no inhiban la identificación y el reconocimiento entre los miembros como poseedores de esquemas mutuamente inteligibles dentro de un grupo, es decir, en el que predomina la identidad del grupo frente a la perspectiva individual. Agrega el autor que para comprender las diferencias grupales, hay que visualizar sus procesos de apropiación de cultura que la diversidad actual trae al aula con cada estudiante que la conforma. Así se comprende que cada individuo apropia el mundo según sus experiencias, vivencias y códigos que lo rodean desde su nacimiento, por lo tanto, ya sea por diferencia étnica, racial o simplemente por situación geográfica, siempre se tendrá en las aulas un complejo sistema de culturas que conforman el multiculturalismo.

Por su parte, Camacho et al. (1982) hablan del multiculturalismo en términos de pluralidad de culturas y afirman que la condición para estudiar los grupos socioculturalmente ajenos al nuestro, es el aceptarlos como relativos de todas las culturas, incluyendo a la que se pertenece, que se debe aceptar la existencia de dicha pluralidad y adoptar los instrumentos conceptuales capaces de entenderlas, más allá de las valoraciones prejuiciosas o inmediatas. Al respecto, Bueno (1998) agrega que, según sean las matizaciones, así se percibe de una manera u otra el multiculturalismo y refiere que Peter McLaren 
plantea que el multiculturalismo significa una aceptación cultural del riesgo que implican la complejidad de las relaciones entre las distintas culturas, explorando la identidad de cada una de ellas dentro de un contexto de poder, discurso y experiencia.

Aquí surge la interrogante de cómo hacen el y la docentes para abordar a sus estudiantes, quienes muchas veces tienen costumbres y creencias que deben ser respetadas como parte de otra cultura y otra visión de mundo. Un hecho puede ser que se deshumaniza por ignorancia, y un aparato estatal, que se transmite a través de la ideología dominante, como la llama Gramsci (1975), es algo difícil de erradicar; en muchos casos, se esconde bajo el glamoroso nombre de "nacionalismo". Llámese de la forma que sea, es simplemente una reproducción de los intereses económicos y políticos de un pequeño grupo en el poder.

La realidad muestra cómo para la mayoría, la cultura propia es la mejor de todas, y se mira a las del lado con ojos de espanto y desagrado; allí comienza la injusticia e impide mirar de cerca y entender que somos tan solo una pequeña parte de una gran mosaico cultural que está presente y no va a desaparecer. Acaso, es más viable y justo esperar que Enrique simplemente se desvanezca con el tiempo, y de esta forma, al negarlo, él no va a crecer y a convertirse en un adulto en la sociedad costarricense.

Es indudable que cada individuo construye su cultura y la apropia y, esta construcción individual lleva muchas veces a creer que somos portadores de la verdad y del don divino de ser los "escogidos", donde cada uno ve según su visión de mundo, con sus propios matices y sonidos, pero no respeta los de otros y otras. En esta misma linea de pensamiento, Camacho et al. (1982, p. 65) comentan que “...la cabal eficiencia del relativismo cultural, no puede provenir sino de la convicción en que la pluralidad de las culturas no sólo existe (y en este sentido no habría pueblos "incultos" ni "ignorantes") sino que debe existir". Esto trae un respiro, una luz que empieza a marcar un camino posible de transitar bajo los términos de la razón y la sensibilidad humanas.

El multiculturalismo no subyace en una posibilidad, es un hecho innegable y presente en cada rincón del planeta. La interrogante que se presenta está en tener la disposición a aceptarlo y lograr ir más allá de lo que se es hoy, ya que la diversidad está latente en cada espacio vital, y presente en las barriadas, en las ciudades, en las escuelas. Se debe, entonces, tomar conciencia que al negar su existencia, o al no mirar las diferencias que se presentan en este abanico cultural, se está cometiendo etnocidio, democidio, y aquellos con mayor poder en su momento cometerán genocidio ante la mirada expectante de todos, ya 
sea con el silencio o con el apoyo; si esto se da, se estaría siendo cómplice de prácticas tan poco humanas que no existen palabras para ubicarlas en un lenguaje de la razón.

Bonilla (2000), en esta misma línea de pensamiento, refiere que el llegar a tomar conciencia de la diversidad, ha sido un proceso doloroso, con resistencias registradas en la memoria de muchos individuos y agrega que reconocer la diversidad va más allá de un ejercicio académico. Es un llamado de atención sobre deudas históricamente heredadas y acumuladas en una monumental cuenta que hay que saldar, tanto con los hombres y las mujeres de hoy y mañana, como con el ambiente y los excluidos del proyecto global.

Deudas que aún siguen siendo cobradas con creces, deudas que los niños y las niñas en las aulas cargan sobre sus espaldas. Muchas veces no solamente el extraño, sino el y la docente, llevan a la exclusión paulatinamente, sin sentir culpa ni arrepentimiento. Esto coloca a la persona en una situación mucho más desventajosa que la que tenía antes de ingresar a la escuela.

Aún así, hay quienes pretenden negar la existencia de una pluralidad de culturas en el aula, en la sociedad, y sobre todo niegan el derecho a ser y vivir como seres humanos diversos con igualdad de derechos. Por esto, se debe refiexionar seriamente sobre la situación que se vive, y comprender que esta no es fácil, que al enfrentarla se remueven miles de creencias y de valores arraigados. El éxito no está en afirmar que se cree en la diversidad y que se vive sin problemas; el éxito está en lograr definirse, entenderse y luego desde la intimidad, acercarse al Otro de tal forma que se pueda lograr mirarlo a los ojos, y descubrir qué hay más allá de ellos.

Al respecto, Fraser (1997), citado por Brosio (2000, p. 405), escribe que:

"... a menos de que yo pueda unirme a una conversación con respeto hacia otros pero también como una persona quien está orgullosa de mis ideas... y que yo pueda colaborar con el encuentro, yo no estaré comprometido en la construcción de una conversación multicultural... En mis relaciones con las personas de color, con mujeres, con todos y todas aquellas que representen diversidad en esta sociedad, yo tengo que tomar el riesgo de decir claramente lo que creo y quién soy yo".

Estas palabras apelan a estar consciente de quién se es, y a estar orgullosos de ello, pero también nos comprometen con la consigna de que no hay nada más delicioso que poder disfrutar de los Otros, y lograr así ser uno más en esta aldea global. La interrogante sería entonces, ¿qué estoy haciendo como 
docente de aulas multiculturales? ¿Qué respuestas estamos dando como ciudadanos de un mundo que crece y se empequeñece a la vez?

La diversidad es un desafío que está presente en cada aula de este país, ya sea personificada por Enrique o por cualquiera de los miles de niños o niñas matriculados; la diferencia consiste en mirarla o ignorarla. El ignorarla no debería ser un actuar permitido en un o una docente, dado que su deber es dar propuestas que llenen las necesidades de sus estudiantes.

Desde esta perspectiva, es muy diferente ser informador a ser un verdadero formador. La diferencia está en lo que se propongan el y la docentes cada día, en el esfuerzo que hagan, y las realidades que se logren incorporar. Confucio dijo: "La naturaleza hace que los hombres nos parezcamos los unos a los otros y nos juntemos; la educación hace que seamos diferentes y que nos alejemos". Entonces, ¿cómo hacer para convertir la propuesta educativa de hoy en una que acerque y no aleje? Es una tarea difícil, que es diferente en cada caso, en cada aula, en cada versión del mundo que se presenta, lo cual representa el desafío, pues debemos aprender a tener una visión multicultural $\mathrm{y}$, además, luchar contra las ideologías dominantes que intentan transmitirse a través del currículo exclusivo que se tiene en nuestro país.

Entwistlet (2000) en su artículo "Educating Multicultural Citizens: Melting Pot or Mosaic?", refiere la problemática que se presenta en países como Estados Unidos y Canadá al intentar dar respuestas al multiculturalismo. Nos muestra dos posiciones en las cuales muchas veces se trata de atender las diferencias culturales, buscando apropiarse del sujeto y obligándolo a hacer suya, de una forma arbitraria, la cultura dominante, donde no solamente pierden su idioma, sino su identidad y en parte, su actuar cultural. Esta práctica el autor la denomina metafóricamente "The Melting Pot". Otra situación es que también se intenta crear sujetos diversos en un mosaico en el que cada pieza debe ser de igual medida; pero al tratar de lograr esta igualdad, se pierde la individualidad, ya que no se puede esperar que todos puedan ser medidos de la misma forma. Se da, en este último caso, un proceso de asimilación o absorción de la individualidad en la cultura dominante.

Ante estas dos propuestas, el autor rescata que tal vez en las discusiones de sociedades multiculturales y el tipo de educación que las personas merecen, se debe evitar la retórica ideológica de ambas metáforas. En lugar de esto, se debe comprometer en una discusión detallada sobre qué necesita una sociedad multicultural saludable para asegurar la justicia para el individuo inmigrante como la necesaria cohesión social para las y los ciudadanos y hacerlos sentir conectados unos con otros para el bien común. 
De acuerdo con lo anterior, se puede resaltar la importancia de la justicia en la educación, entendiendo justicia no como la igualdad de oportunidades para cada uno sin distinción, sino como el brindar las oportunidades a cada uno en la medida en que su cultura lo necesite, tomando en cuenta las diferencias y rescatándolas en beneficio del bien común.

En relación con lo anterior, Bueno (1998, p. 4) refiere que "la educación multicultural privilegia el estudio del conocimiento y las culturas de los distintos grupos, minoritarios y mayoritarios, que conviven en una sociedad plural y múltiple, con una intención de comprensión y comunicación entre ellos”. Esto beneficia tanto al estudiante, como al grupo en general, ya que la diversidad enriquece, y sobre todo ayuda a tener diferentes perspectivas de situaciones diversas o problemas que no se tendrían en un grupo homogéneo.

Por otro lado, en la actualidad, también se habla de fracaso escolar, teniendo en cuenta que en un salón multicultural se doblan las probabilidades de fracaso de quienes no son atendidos y que suelen ser marginados, o se ven en desventaja, tal y como Enrique lo ejemplifica luego de haber fracasado año tras año; esto demuestra que el y la estudiantes fracasan por una falla en el sistema educativo, no porque tengan dificultades para aprender. En este sentido, Tan (2000) manifiesta que hay evidencias que dicen que aquellos estudiantes de minorías raciales que sienten que sus docentes valoran el multiculturalismo y la diversidad, y lo respetan, alcanzarán mayores logros en la clase y tendrán menos riesgo de desertar, en comparación con quienes viven la situación opuesta.

Asimismo, Hagiwara (1998) comenta que, al agregar multiculturalismo al programa de clases, se promueve no sólo la tolerancia y la aceptación, sino también se motiva a la apertura de las diferencias culturales. El y la docentes son la clave para lograr exitosamente cualquier propuesta pedagógica con un enfoque multicultural. Las universidades deben servir para preparar a los y las docentes y así darles los instrumentos que necesiten en un futuro para trabajar en un salón de clases multicultural. En relación con lo anterior, Tan (2002) dice que un análisis de documentos para una reforma de la Enseñanza de la Educación, incluyendo aquellos de la Comisión Nacional de la Excelencia en Educación (1985) y The Camegie Forum (1986), muestran que dos de las más fuertes recomendaciones son que los Programas de Educación deben asegurar preparación para control de la disciplina y desarrollar competencia multicultural en los y las estudiantes.

Cabe aquí la interrogante de si las universidades están tomando en cuenta la realidad actual y preparándose para enfrentarla o, solamente reproducen 
modelos ya obsoletos que ponen en una posición de incompetencia profesional a el y la docentes frente a grupos tan heterogéneos. Se sabe que Estados Unidos así como Canadá y muchos otros países, han tenido que realizar revisiones a sus propuestas pedagógicas debido a la cantidad de migrantes que, año con año, ingresan a sus países. Los y las docentes no solamente deben enfrentar a estudiantes con bagajes culturales diferentes, sino también con idiomas distintos, lo cual dificulta más el proceso de enseñanza y aprendizaje.

En Costa Rica, los y las docentes, en una gran mayoría, no hemos sabido cómo atender a la población culturalmente diversa y esto, se sabe de antemano, no es sencillo. Según nos comenta Martín (2002), el multiculturalismo presenta diferentes vertientes que vienen de comunidades nuevas provenientes de distintas geografías con universos culturales y mentales diferentes, lo cual no puede ser entendido sin antes pasar por todo un proceso de transformación y adecuación mutuas. Lo más difícil de esto es darle reconocimiento a la pluralidad y aceptar su existencia en el aula; esto puede hacerlo el y la docentes desde su intimidad, en reflexión profunda consigo mismo y con una actitud llena de vocación y formación profesional.

Al respecto, Tan (2002) agrega que, las y los docentes con competencia multicultural, podrán enseñar en aulas racialmente diversas, tener un entendimiento más profundo de las diversas culturas y ser capaces de tratar con los asuntos políticos y sociales complejos que afectan el fracaso o el éxito del estudiante.

Aquí surge la interrogante sobre la relación que existe entre el currículo y el aula multicultural. En este sentido, Campani (1996) manifiesta que el currículo en sí es el resultado de un proceso de selección de los saberes considerados dignos de ser preservados y agrega que dicha selección se desglosa en tres estadios, y que hay enseñantes, académicos y politicos en los procesos de desición sobre los saberes; refiere que el poder que tienen los enseñantes sobre lo que debe ser enseñando, está ejemplificado en la autonomía de las universidades, y este poder, a pesar de ser real, debe tener en cuenta las funciones de la escuela en relación con el Estado y, por ende, con las exigencias políticas.

Es pertinente rescatar que se debe abogar por un modelo de currículo flexible y cambiante, tan cambiante como la cultura misma, que no se queda estática en ninguna de sus manifestaciones. Un modelo que contemple las necesidades de cada persona y·le ofrezca al individuo una oferta pedagógica que englobe la identidad como algo que se construye conforme pasa el tiempo, individual y grupalmente, con mezclas y combinaciones que solo pueden producirse en la cotidianeidad, y de la cual la escuela forma parte de ella. 
Es difïcil que las barreras que impone el Estado, con sus intereses, sean franqueadas; pero la posibilidad existe en tanto que se crea en ella y se luche por ella. Los cambios se dan primero en ámbitos pequeños y se debe soñar que, poco a poco, irán abarcándolo todo. Es tiempo de pedirle a los políticos que respondan a las necesidades, y si no escuchan, hay que seguir pidiendo más fuerte aún; es momento de que los y las docentes busquen lo que se necesita en sus propias aulas e investiguen para mejorar el currículo y darles mayores oportunidades a sus estudiantes. Sobre todo, es momento de que los académicos y las académicas universitarias se pronuncien, con ideas y actos.

Besalú (1996) nos dice que de diferentes supuestos que se deben tomar en cuenta a la hora de hacerle frente ai currículo en una escuela multicultural, el primero de ellos es el saber que no basta con cambiar los temarios de las materias, sino que también hay que efectuar un cambio en las condiciones contextuales en las que se implementan dichas materias. Comenta que la cultura de la enseñanza obligatoria debe ser una oferta de validez para todos, y cita a Gimeno (1992), quien menciona: "el currículo común no se ha de entender nada más como la suma de contenidos en que todos están de acuerdo ni, mucho menos, como una posición que omite las diferencias" (p. 1).

Se sabe que cambiar el currículo en el sistema educativo costarricense es más que un gran trabajo, es una lucha; pero como Meléndez (2002) agrega: "es urgente hacer ver a los responsabíes de diseñar y administrar la Educación que, contrario a lo predicho, las oportunidades de desarrollo se construyen con la participación equitativa de todos los miembros de una comunidad escolar inclusiva; que es esencialmente diversa y que, cuánto más diversa sea, más alternativas podrá aportar a la lucha permanente por el desarrollo, la justicia, la salud, la seguridad, la paz y la sobrevivencia"

Propuestas como estas, y muchas otras más, son los primeros pasos para teorizar sobre el tema y encontrar una posición que ayude al país, que dista mucho de ser homogénea en todo su territorio, y mucho más, a otros lugares con presencia de población indígena en el aula, quienes enfrentan dificultades adicionales debido al idioma materno y todo lo que ello significa culturalmente.

En esta misma línea, se puede mencionar a Besalú, quien agrega que el currículo escolar se ha construido con una perspectiva de grupo mayoritario dominante en la sociedad; de ailí nacen los sentimientos de superioridad cultural en los estudiantes de los grupos mayoritarios, "privados como quedan de examinar críticamente su cultura y de conocer otros puntos de vista y otras 
experiencias culturales, y sentimientos de inferioridad social y cultural entre los alumnos de los grupos minoritarios, que no ven reflejada su cultura en la escuela, o cuando aparece estereotipada y desvalorizada" (1996, p. 4).

Este autor propone que los Estudios Sociales sirvan al y la estudiantes para descifrar el mundo, lo que implica un conocimiento de la realidad, todo esto para tener ideas claras en cuanto a política y aspectos sociales. Para ello, plantea una enseñanza que contemple dedicar tiempo a la explicación de la problemática y acontecer actual, la introducción en el currículum de información sobre las culturas, religiones y las formas de vida. Por último, y muy acertadamente, agrega que "si queremos hacer de nuestros alumnos personas críticas y solidarias, hemos de darles información objetiva y alternativa, para que puedan entender cuáles son las causas estructurales que hacen que las tres cuartas partes de la población mundial vivan en condiciones de miseria" (p. 4).

En cuanto a lo anterior, se debe hacer énfasis en que al abordar la multiculturalidad en el aula el y la docentes deben tener una posición de apertura y enseñar sin impartir ningún tipo de currículum oculto a sus estudiantes; hoy en día, en nuestros centros educativos, se puede estudiar la realidad, pero en muchos de los casos está teñida por lo que el y la docentes piensan de ella. Esta subjetividad provoca que cualquier propuesta, por buena que sea, se pierda por docentes que aún no han descubierto las múltiples posibilidades que ofrece, tanto para sí mismos como para sus estudiantes, el enseñar en y para la diversidad.

Es importante subrayar la necesid̈ad de cumplir con una fórmula simple, pero que exige mucho de los y las docentes. Se debe saber que al enfrentarse a una escuela multicultural por obligación, hay que estudiar las culturas, apropiarse de los conocimientos necesarios para poder realizar propuestas de validez $y$, sobre todo, nunca olvidar que se debe imaginar cada día un salón de clases mejor.

Es un momento para exaltar el valor de la utopía, tan necesaria en tiempos convulsos como los actuales, en los que muchos creen que se ha perdido el derecho a soñar, lo cual es inaceptable, porque solamente a través del deseo de un mejor mañana, se comenzará a modificar el presente y forjar un futuro diferente. Está claro que no basta con soñar, sino que se deben tener las herramientas necesarias que ayuden a moldear esta escuela multicultural que hoy se trata de construir, llena de oportunidades para cada uno de los niños y niñas que la componen. He aquí la fórmula a seguir: conocimientos más deseos de descubrir y crear junto con nuestros estudiantes. 
En este punto, nada mejor que mencionar las palabras de Argullo y Trias, citados por Pérez (1998, p. 55), quienes dicen: "las perspectivas utópicas son convenientes porque entrañan la necesidad de poner a uno a prueba, y la voluntad de modificar, el propio espacio en que uno se encuentra. Son, por llamarlas con otro nombre, las perspectivas del deseo... Lo peor que podría ocurrimos sería aceptar una sociedad, y una vida, sin deseo. El deseo siempre implica una tensión entre el espacio que habitas y un espacio eventual que se proyecta en tu mente y en tu sensibilidad".

La vida sin deseo es algo que nadie debe estar dispuesto a aceptar, se debe vivir la utopía y trabajar por ella, en la cual se ha de desarrollar la escuela hoy, llena de pluralismo y sensibilidad. En esta utopía, recaen todas las esperanzas de Enrique y de miles de niños y niñas como él; por eso, es necesario que esa tensión que implica el deseo entre lo que se es y lo que se quiere ser, toque a los y las docentes de tal manera que se comprometan a realizar pequeños cambios en sus parcelas de vida, que al final en conjunto resultarán en grandes cambios para el modelo educativo costarricense. 


\section{REFERENCIAS}

Alvarenga, P. (1997). Conflictiva convivencia los nicaragüenses en Costa Rica. Cuaderno de Ciencias Sociales 101. San José, Costa Rica: FLACSO.

Álvarez, N. (2002). Multiculuralismo e inmigración: Retos Ideológicos del Siglo XXI. Cuadernos Electrónicos de Filosofia del Derecho. España: Universidad de Alcalá. En línea: http: www.uv.es/CEFD/5/alvarez.html

Barberousse, P. (2001). Globalización y Posmodernidad: Desafios al Aprendizaje. Revista EDUCARE, II, 9-25.

Barberousse, P. (2003). Buscando respuestas al reto de la diversidad desde la pedagogía crítica. Revista EDUCARE, IV , 21-30.

Benedetti, M. (1980). Inventario. Poesía 1950-1980. Madrid, España: VISOR Libros.

Besalú, X. (1996). Curriculum y multiculturalismo en la escuela. Sobre iterculturalitat. Documents de treball del la cinquena i sisena Escola d'Estuit sobre interculturalitat i del primer i segon Fórum Intercultural. En línea: http: www. uv.mx/dei/P_publicaciones/BasesTeoricas/BesaluXavier.htm

Bonilla, V. (2000). Diversidad: Retos para una educación inclusiva. Revista Educare, II, 89-96

Brosio, R. (2000). Issues and arguments concerning class, gender, race and other "identities". Educational Studies (American Educational Studies Association) 31, 393-406

Bueno, J. (1998). Controversias en torno a la educación multicultural. Coruña, España: Universidad de La Coruña, Facultad de CC. de la Educación.

Camacho, D., Mayorga, R., De Ipola, E., Najenson, J., De Riz, L., Nun, J. (1982). América Latina: Ideología y cultura. San José, Costa Rica: Ediciones FLACSO.

Campani, G. (1996). La pedagogía intercultural: una perspectiva para el futuro. Documents de treball del la cinquena i sisena Escola d'Estuit sobre interculturalitat i del primer i segon Fórum Intercultural. En línea: http:

www.uv.mx/dei/P_formacion/Diversidad_2001/Besalu.htm

Entwistlet, H. (2000). Educating multicultural citizens: Melting pot or mosaic. International Journal of Social Education 14, 1-15.

Gallego, I. Entrevista a Mikel Azurmendi. El Parche Digital. En línea: http: www. elparchedigital.com $\backslash$ pags $\backslash$ sociedad_2.htm

Gramsci, A. (1975). Los intelectuales y la organización de la cultura. México, Editorial Juan Pablos.

Gimeno, S. (1988). Poderes Inestables en Educación. Madrid, España: Morata.

Hagiwara, T. (1998). Introduce multiculturalism in your classroom. Intervention in school and Clinic 34, 43-44. 
López, M. (s.f.). La educación intercultural: la diferencia como valor. En línea: http: www.sauce.cnice.mecd.es/smarti4/lopezm.htm

Martín, M. (2002). El velo y la escuela. Revista de Prensa: El País. En línea: http: www.pangea.org/ariadna/velo-esc-GemaMartin.htm

Meléndez, L. (2002). Atención a la diversidad personal y cultural en el escenario educativo centroamericano. Ciclo de Conferencias - 2002. Centro Nacional de Recursos para la Inclusión Educativa. 11 de noviembre de 2002.

Pérez, A. (1998). La cultura escolar en la sociedad neoliberal. Madrid, España: Ediciones Morata, S.L.

Tan, G. (2002). The need for multiculturalism in the classroom as perceived by Mexican American schoolchildren. United States of America. Multicultural Education 9, 21-24. 